05

\title{
Возврат и рекристаллизация в лентах из сплавов на основе никеля с разным направлением легкого намагничивания в условиях отжига в сильном магнитном поле
}

\author{
(С) И.В. Гервасьева, ${ }^{1}$ В.А. Милютин, ${ }^{1}$ E. Beaugnon, ${ }^{2}$ В.А. Казанцев, ${ }^{1}$ Ю.В. Хлебникова, ${ }^{1}$ Д.П. Родионов ${ }^{1}$ \\ ${ }^{1}$ Институт физики металлов им. М.Н. Михеева УрО РАН, \\ 620990 Екатеринбург, Россия \\ ${ }^{2}$ Univ. Grenoble Alpes, CNRS-LNCMI, \\ Grenoble, France \\ e-mail: gervasy@imp.uran.ru
}

(Поступило в Редакцию 29 декабря 2015 г.)

Сплавы $\mathrm{Ni}_{48.8} \mathrm{Fe}_{51.2}$ и $\mathrm{Ni}_{70} \mathrm{Co}_{30}$, подвергнутые холодной прокатке на 98.8-99.0\%, отжигались в сильном постоянном магнитном поле до $29 \mathrm{~T}$, а также без поля при разных температурах. Исследовалось влияние поля на структуру и кристаллографическую текстуру. Обнаружено, что приложение внешнего магнитного поля задерживает процессы возврата и ранних стадий рекристаллизации. На стадии роста зерен при дальнейшем их развитии происходит усиление количества ориентировок с направлением легкого намагничивания и увеличение размера соответствующих зерен при условии, что направление легкого намагничивания совпадает с основной ориентировкой текстуры, характерной для данного материала. Если направление легкого намагничивания не совпадает с получаемой текстурой, то рост зерен в поле задерживается, и острота текстуры уменьшается.

\section{Введение}

Появившиеся в последние годы работы по влиянию сильного постоянного магнитного поля на процессы диффузионно контролируемых превращений при термической обработке материалов обобщены, в частности, в обзорах $[1,2]$. Исследования касаются изменений структуры и текстуры при диффузионных фазовых превращениях, а также кинетики рекристаллизации и образования преимущественных ориентировок в однофазных материалах. Возросший интерес к этой области исследований обусловлен появлением мощных установок по созданию сильных постоянных магнитных полей до 30 Т и более с возможностью поддержания высоких температур внутри таких электромагнитов. Приложение сильного магнитного поля при отжиге материалов может быть перспективным методом воздействия на структуру, кристаллографическую текстуру, фазовый состав и соответственно на получение необходимых функциональных свойств. Однако до сих пор нет единой точки зрения по поводу причин влияния сильного поля на структуру и текстуру материалов, а, значит ограничены и способы его целенаправленного применения. В качестве причины часто называется энергетический стимул выстраивания направления легкого намагничивания в процессе структурных превращений в направлении приложенного внешнего поля. В некоторых работах говорят о роли магнитострикции в формировании структуры и текстуры. В нашей работе [3] показано, что отжиг прокатанного сплава $\mathrm{Ni}_{48.8} \mathrm{Fe}_{51.2}$ при температурах до начала рекристаллизации в сильном постоянном магнитном поле 20 Т замедляет процессы возврата и одновременно способствует формированию структурных областей с направлением легкого намагничивания $\langle 001\rangle$. Нагрев производился посадкой в печь.

В дальнейших исследованиях была поставлена задача сравнить действие сильного магнитного поля на процессы, происходящие при отжиге в ферромагнитных материалах с разным направлением легкого намагничивания. Была проведена обработка в поле 20 и 29 Т с медленным нагревом до температуры отжига двух сплавов на основе никеля. В первом $\left(\mathrm{Ni}_{48.8} \mathrm{Fe}_{51.2}\right)$ - направлением легкого намагничивания является кристаллографическое направление $\langle 001\rangle$, во втором $\left(\mathrm{Ni}_{70} \mathrm{Co}_{30}\right)-\langle 111\rangle$. Константа магнитной анизотропии при добавлении кобальта к никелю меняется немонотонно - от отрицательного значения для чистого никеля к положительным величинам в области 5-20\% Со и затем снова опускается в отрицательную область [4]. Указанные сплавы были выбраны еще и потому, что и в том, и в другом в результате рекристаллизации после обычного отжига без поля образуется достаточно острая кубическая текстура $\{100\}\langle 001\rangle[5,6]$. Основные результаты по сплаву $\mathrm{Ni}_{70} \mathrm{Co}_{30}$ приведены в работе [7]. В настоящей работе приводятся новые данные для сплава $\mathrm{Ni}_{48.8} \mathrm{Fe}_{51.2}$, которые сравниваются с данными, полученными в работе [7].

\section{Материал и методика эксперимента}

Сплавы никеля с Fe и Co были выплавлены в алундовых тиглях в атмосфере аргона в индукционной печи. Был использован электролитический никель чистотой 99.99\%. Легирующие элементы имели чистоту не менее 99.94\%. После горячей ковки слитков $1000-800^{\circ} \mathrm{C}$ были получены прутки сечением $10 \times 10 \mathrm{~mm}$. После шлифовки и отжига в вакууме при температуре $850^{\circ} \mathrm{C}$ 

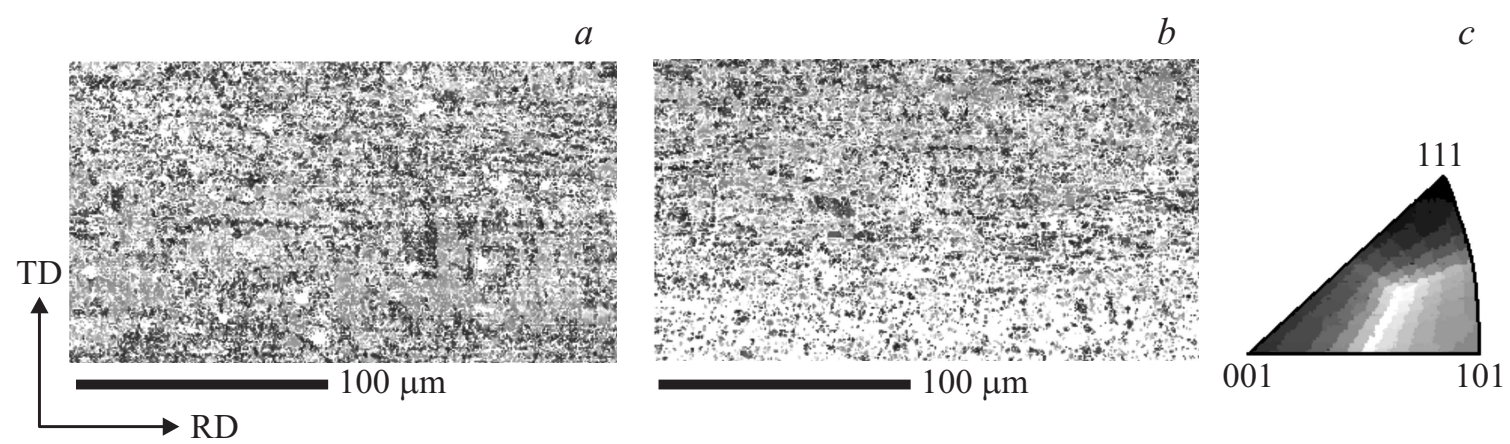

Рис. 1. Ориентационные карты EBSD сплава $\mathrm{Ni}_{48.8} \mathrm{Fe}_{51.2}$ после отжига при $500^{\circ} \mathrm{C}$ с медленным нагревом и выдержкой 20 min без поля $(a)$, в поле 29 T $(b)$ и положение ориентировок на стереографическом треугольнике $(c)$.

в течение $1.5 \mathrm{~h}$ из прутков были получены заготовки прямоугольного сечения. Холодную деформацию заготовок с высокими степенями обжатия осуществляли на двувалковом прокатном стане до толщины $80-100 \mu \mathrm{m}$ при числе проходов 40-50. Степень холодной деформации составляла $98.8-99.0 \%$. Средний размер зерна в заготовках перед прокаткой не превышал $40 \mu \mathrm{m}$.

Образцы размером $5 \times 25 \mathrm{~mm}$ были вырезаны вдоль направления прокатки ленты и помещены в вакуум в кварцевые ампулы с внешним диаметром $9.5 \mathrm{~mm}$. Подготовленные таким образом образцы отжигали в Лаборатории сильных магнитных полей в Гренобле (Франция) в постоянном магнитном поле напряженностью 0,20 и $29 \mathrm{~T}$. Сплавы $\mathrm{Ni}_{48.8} \mathrm{Fe}_{51.2}$ и $\mathrm{Ni}_{70} \mathrm{Co}_{30}$ отжигались с медленным нагревом со скоростью примерно $10^{\circ} / \mathrm{min}$, начиная с $300^{\circ} \mathrm{C}$ до температур $500^{\circ} \mathrm{C}$ с выдержкой $20 \mathrm{~min}$ и $550^{\circ} \mathrm{C}$ с выдержкой $30 \mathrm{~min}$ соответственно. Точка Кюри первого сплава составляла $500^{\circ} \mathrm{C}$, второго $680^{\circ} \mathrm{C}$, т.е. отжиг проводился в ферромагнитном состоянии. Температура начала первичной рекристаллизации в условиях немагнитного отжига составляла для сплава $\mathrm{Ni}_{48.8} \mathrm{Fe}_{51.2}-563^{\circ} \mathrm{C}$, для сплава $\mathrm{Ni}_{70} \mathrm{Co}_{30}-400^{\circ} \mathrm{C}$.

Образцы сплава $\mathrm{Ni}_{48.8} \mathrm{Fe}_{51.2}$ после отжига при $500^{\circ} \mathrm{C}$ нагревались в кварцевом дилатометре Ulvac Sinku-riku в интервале температур от 400 до $675^{\circ} \mathrm{C}$ со скоростью нагрева $2 \%$ min для определения температурного интервала протекания рекристаллизации по изменению коэффициента термического расширения сплава.

Одновременный анализ структуры и ориентировок в рекристаллизованных образцах проводили методом дифракции обратно отраженных электронов (EBSD), заключающемся в расшифровке картин Кикучи с помощью специальной приставки фирмы EDAX в сканирующем электронном микроскопе „FEI Quanta 200“. Шаг при сканировании составлял $2 \mu \mathrm{m}$, увеличение 400 . Перед исследованием образцы электролитически полировались. Объемную долю разных кристаллографических плоскостей на поверхности ленты рассчитывали в пределах рассеяния $\pm 10^{\circ}$. Средний размер зерна после первичной рекристаллизации определяли методом секущей вдоль направления ленты по картинам качества изображения EBSD.
Исследование структуры сплава $\mathrm{Ni}_{48.8} \mathrm{Fe}_{51.2}$ после дорекристаллизационного отжига при $500^{\circ} \mathrm{C}$ осуществляли методом EBSD на сканирующем микроскопе высокого разрешения Carl Zeiss Auriga в Центре коллективного пользования Уральского федерального университета. Шаг при съемке составлял $0.5 \mu \mathrm{m}$.

Средний размер зерна в рекристаллизованных образцах определялся методом секущих по изображениям структуры, полученных на сканирующем микроскопе.

\section{Результаты и их обсуждение}

Образцы сплава $\mathrm{Ni}_{48.8} \mathrm{Fe}_{51.2}$ после отжига при $500^{\circ} \mathrm{C}$ претерпевали только возврат. В работе [3] было показано, что приложение магнитного поля 20 Т при отжиге таких образцов с быстрым нагревом на температуру $490^{\circ} \mathrm{C}$ задерживает процессы возврата. О замедлении процессов разупрочнения можно было судить по ухудшению качества картин Кикучи при исследовании методом EBSD, а также по более высоким значениям микротвердости после магнитного отжига. В настоящей работе образцы, подвергнутые дорекристаллизационному отжигу с медленным нагревом при $500^{\circ} \mathrm{C}$, исследовали методом EBSD на сканирующем микроскопе высокого разрешения Carl Zeiss Auriga. На рис. 1 приведены ориентационные карты, полученные с образцов, отожженных без поля (рис. $1, a$ ), и в поле 29 Т (рис. $1, b)$. Неокрашенные области на ориентационных картах означают, что расшифровка картин Кикучи в этих местах невозможна, что, в свою очередь, свидетельствует о существенных искажениях кристаллографической решетки. Из рис. 1 видно, что качество расшифровки картин Кикучи намного ниже в образце после магнитного отжига, т.е. процессы разупрочнения затормаживаются под действием сильного магнитного поля.

Можно предположить, что такое торможение должно приводить к сдвигу интервала протекания первичной рекристаллизации в область более высоких температур. К сожалению, проведение эксперимента по отжигу в магнитном поле не предполагало одновременного использования дилатометра для определения аномалий, свидетельствующих о температурном интервале протекания рекристаллизации в образцах. Поэтому в работе 


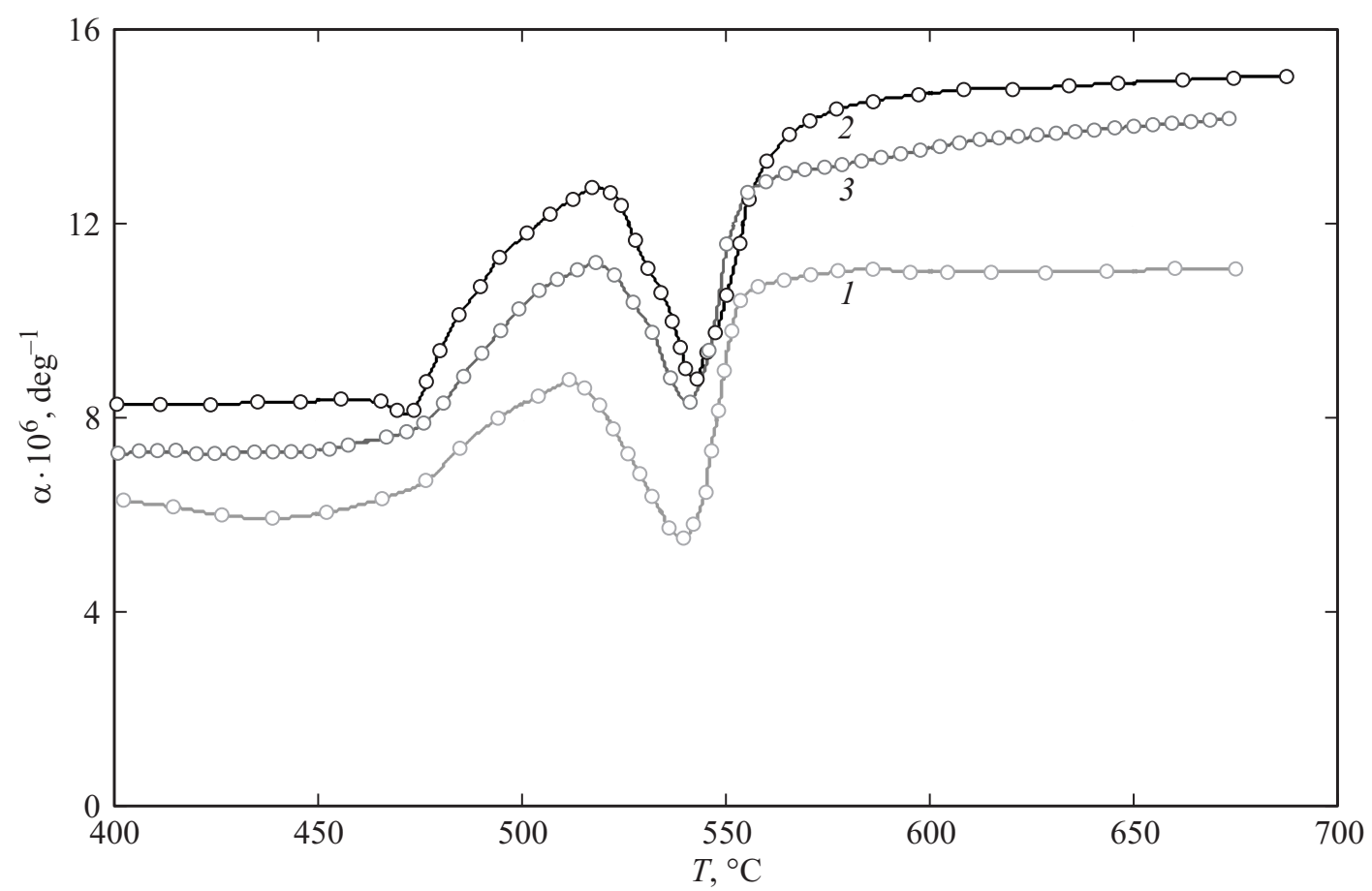

Рис. 2. Изменение коэффициента температурного линейного расширения при нагреве со скоростью $2 \mathrm{deg} / \mathrm{min} \mathrm{cплава} \mathrm{Ni}_{48.8} \mathrm{Fe}_{51.2}$, предварительно отожженного при $500^{\circ} \mathrm{C}$ без поля (1), в поле $20 \mathrm{~T}(2)$ и $29 \mathrm{~T}$ (3).

была сделана попытка исследовать эту аномалию на образцах уже предварительно отожженных в магнитном поле при $500^{\circ} \mathrm{C}$. На рис. 2 приведены дилатометрические кривые исследованных образцов. Нагрев начинался с $400^{\circ} \mathrm{C}$ и заканчивался при $675^{\circ} \mathrm{C}$, при этом, естественно, все образцы до начала рекристаллизации дополнительно разупрочнялись. Положение пика дилатометрической аномалии менялось от $539^{\circ} \mathrm{C}$ для образца, предварительно отожженного без поля, до $543^{\circ} \mathrm{C}$ для образца после магнитного отжига. Разумеется, разница в 4 градуса слишком мала, чтобы сделать однозначный вывод, однако тенденция смещения температуры рекристаллизации в область более высоких температур наблюдается.

Образцы, подвергнутые отжигу в процессе дилатометрического исследования до конечной температуры $675^{\circ} \mathrm{C}$, были исследованы методом EBSD в сканирующем микроскопе. На рис. 3 приведены фрагменты ориентационных карт и картин качества расшифровки линий Кикучи для образцов с предварительным дорекристалли- зационным отжигом при $500^{\circ} \mathrm{C}$ без поля (рис. $\left.3, a, e\right)$, в поле $20 \mathrm{~T}$ (рис. $3, b, f)$ и в поле $29 \mathrm{~T}$ (рис. $3, c, g$ ). Картины качества расшифровки картин Кикучи в данном случае приведены для того, чтобы более четко показать зеренную структуру образцов. Обращает на себя внимание то, что размер зерна после обработки, включающей в себя отжиг в поле 29 Т, существенно больше, чем после обработки без поля. Другим ярко проявившимся отличием в структуре образцов, претерпевших термическую обработку в магнитном поле, и образцов, испытавших такую же обработку, но без поля, оказалось изменение в кристаллографической текстуре. По цветным ориентационным картам (рис. $3, a-c$ ) видно, что количество „красных“ ориентировок, изображающих ориентировки, близкие к кубической $\{100\}$, существенно увеличивается с повышением величины поля, т.е. распределение соответствующих ориентировок относительно внешних направлений образца становится более острым. Это также можно видеть по распределению полюсов $\{100\}$ на

Изменение среднего размера зерна $D$ и объемной доли компонентов $\{100\}$ и $\{112\}$ с рассеянием $\pm 10^{\circ}$ в исследованных сплавах после указанных обработок

\begin{tabular}{|c|c|c|c|c|c|c|}
\hline \multirow[t]{2}{*}{$H, \mathrm{~T}$} & \multicolumn{3}{|c|}{$\begin{array}{c}\mathrm{Ni}_{48.8} \mathrm{Fe}_{51.2} \text { после магнитного отжига при } 500^{\circ} \mathrm{C} \\
\text { и отжига без поля до } 670^{\circ} \mathrm{C}\end{array}$} & \multicolumn{3}{|c|}{$\mathrm{Ni}_{70} \mathrm{Co}_{30}$ после магнитного отжига при $550^{\circ} \mathrm{C}$} \\
\hline & $D, \mu \mathrm{m}$ & $\{100\}, \%$ & $\{112\}, \%$ & $D, \mu \mathrm{m}$ & $\{100\}, \%$ & $\{112\}, \%$ \\
\hline 0 & 31.5 & 49.1 & 3.1 & 78 & 81.8 & 1.0 \\
\hline 20 & 32.2 & 91.6 & 0.3 & 70 & 72.2 & 1.9 \\
\hline 29 & 49.4 & 97.5 & 0.2 & 49 & 73.7 & 1.8 \\
\hline
\end{tabular}



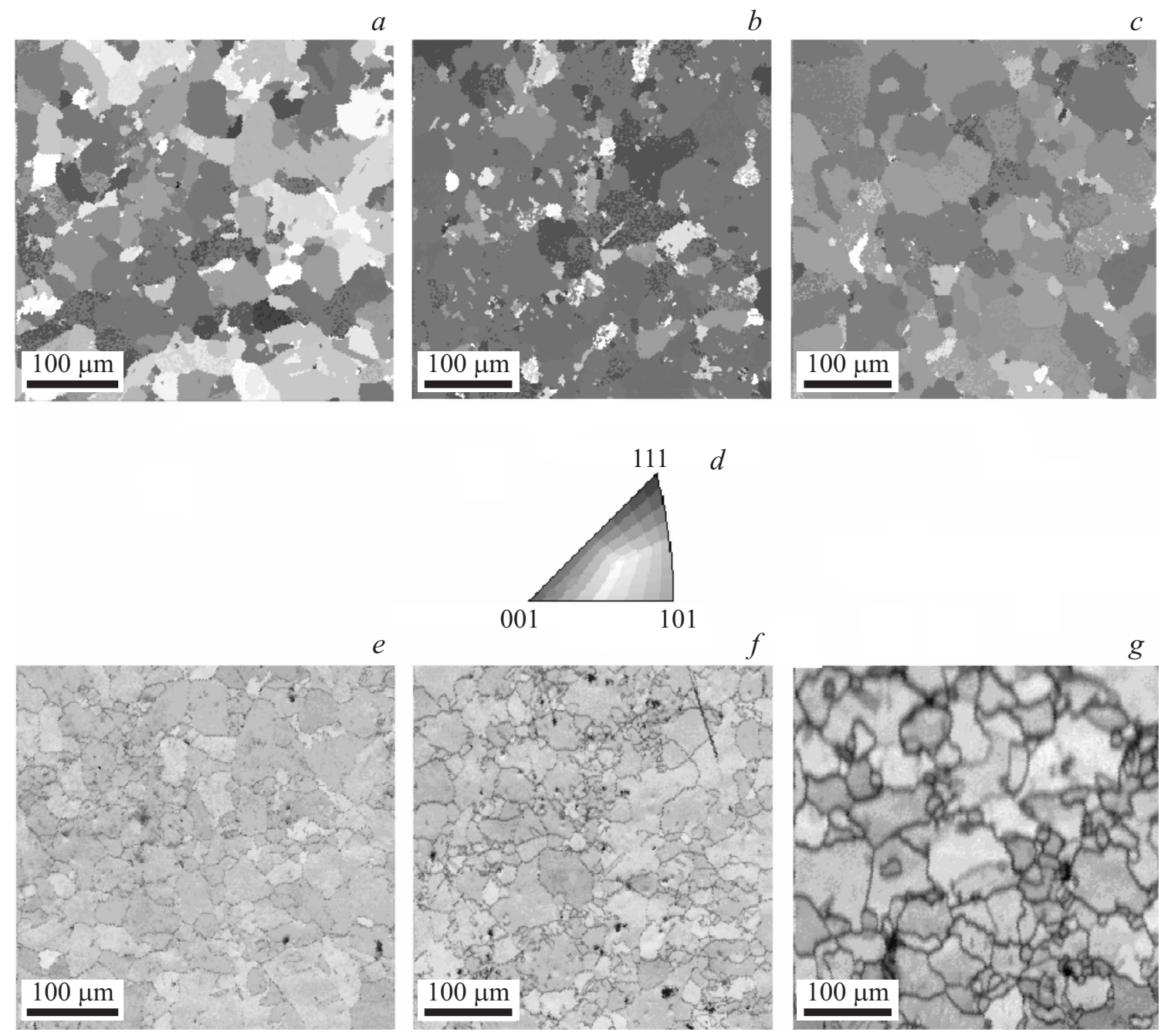

$f$

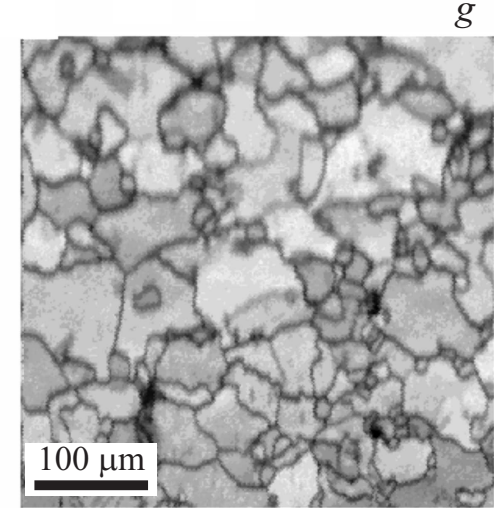

Рис. 3. Ориентационные карты $(a-c)$, картины качества расшифровки линий Кикучи $(e-g)$ и стереографический треугольник с расшифровкой ориентаций $(d)$ сплава $\mathrm{Ni}_{48.8} \mathrm{Fe}_{51.2}$ после медленного нагрева до $675^{\circ} \mathrm{C}$ с предварительным дорекристаллизационным отжигом при $500^{\circ} \mathrm{C}$ без поля $(a, e)$, в поле $20 \mathrm{~T}(b, f)$ и $29 \mathrm{~T}(c, g)$.

полюсных фигурах, построенных по результатам EBSD анализа (рис. $4, a-c$ ). На этом же рисунке приведены такие же полюсные фигуры для образцов сплава $\mathrm{Ni}_{70} \mathrm{Co}_{30}$, отожженных при температуре $550^{\circ} \mathrm{C}, 30 \mathrm{~min}$. Можно видеть, что в этом сплаве острота кубической текстуры при увеличении поля не увеличивается, а уменьшается. В таблице приведены количественные характеристики структуры и ориентировок, формирующихся в сплавах $\mathrm{Ni}_{48.8} \mathrm{Fe}_{51.2}$ и $\mathrm{Ni}_{70} \mathrm{Co}_{30}$ при отжиге в магнитном поле 20 и $29 \mathrm{~T}$, а также без поля при указанных термических обработках. В сплаве $\mathrm{Ni}_{48.8} \mathrm{Fe}_{51.2}$ с направлением легкого намагничивания $\langle 001\rangle$ приложение магнитного поля при дорекристаллизационном отжиге способствует резкому возрастанию объемной доли кубической ориентировки с $49.1 \%$ после отжига без поля до 91.6 и $97.5 \%$ после отжига в поле 20 и $29 \mathrm{~T}$ соответственно. Количество плоскостной ориентировки $\{112\}$, которая входит в одну из основных компонент исходной текстуры деформации $\{112\}\langle 111\rangle$ при этом уменьшается с 3.1 до 0.3 и $0.2 \%$.
В сплаве $\mathrm{Ni}_{70} \mathrm{Co}_{30}$ с направлением легкого намагничивания $\langle 111\rangle$ приложение магнитного поля, наоборот, уменьшает количество кубической компоненты, ее объемная доля меняется с $81.8 \%$ после отжига без поля до 72.2 и $73.7 \%$ после отжига в поле 20 и 29 Т соответственно. Количество плоскостной ориентировки $\{112\}$ при этом слегка увеличивается с 1.0 до 1.9 и $1.8 \%$. Поскольку эта плоскость принадлежит исходной ориентировке текстуры деформации $\{112\}\langle 111\rangle$, которая содержит направление легкого намагничивания $\langle 111\rangle$ для этого сплава, такое увеличение может свидетельствовать о стимулировании роста ориентировок с направлением легкого намагничивания в магнитном поле. Тем не менее видно, что энергия магнитной анизотропии не может играть определяющую роль в формировании текстуры рекристаллизации, главными движущими силами остаются энергия, запасенная при холодной деформации, и энергия границ зерен. Средний размер зерна после первичной рекристаллизации в исследованных сплавах 


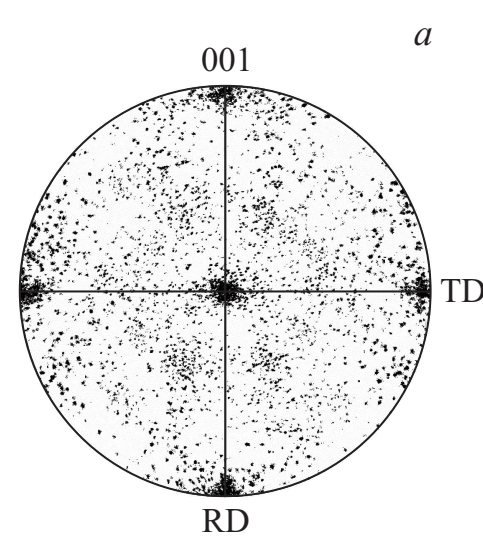

$d$

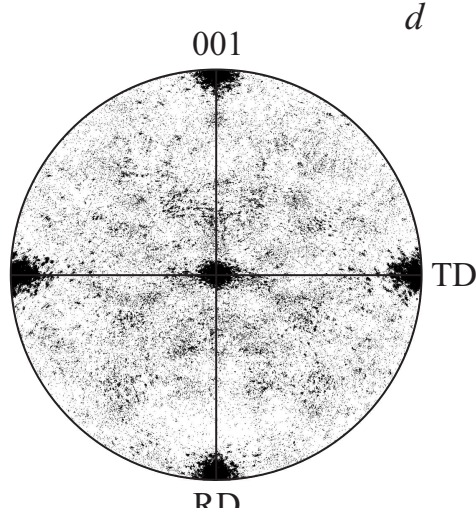

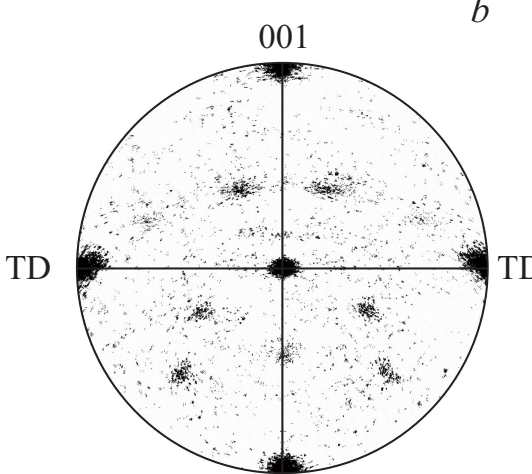

$\mathrm{RD}$

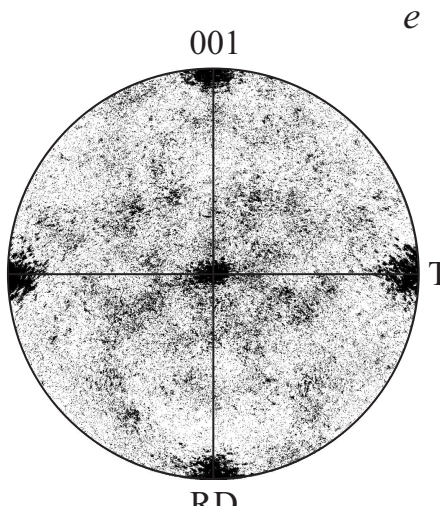

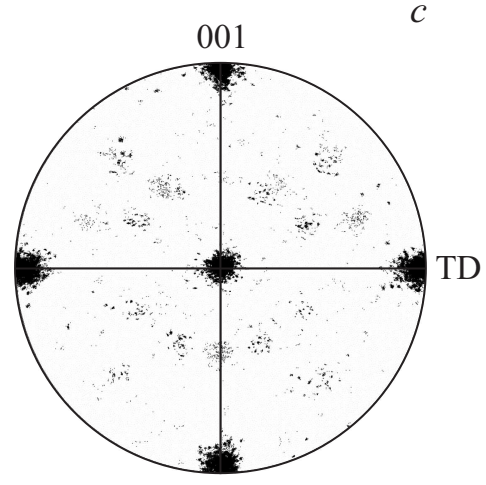

$\mathrm{RD}$
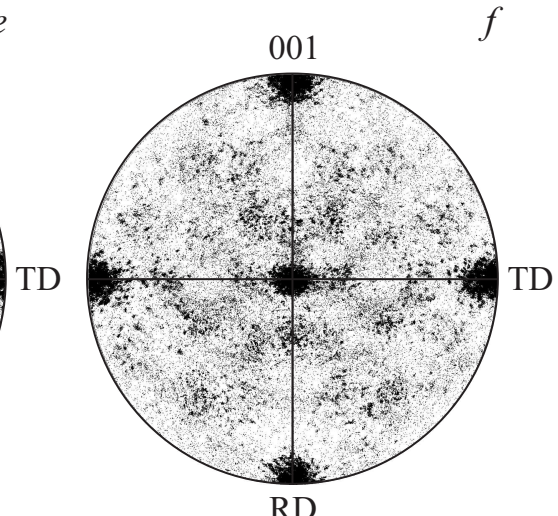

Рис. 4. Полюсные фигуры, полученные методом EBSD, для сплавов $\mathrm{Ni}_{48.8} \mathrm{Fe}_{51.2}(a-c)$ и $\mathrm{Ni}_{70} \mathrm{Co}_{30}(d-f)$, отожженных без поля $(a, d)$, в поле $20(b, e)$ и $29(c, f)$ Т. Температура отжига сплавов $\mathrm{Ni}_{48.8} \mathrm{Fe}_{51.2}$ и $\mathrm{Ni}_{70} \mathrm{Co}_{30}-675$ и $550^{\circ} \mathrm{C}$ соответственно. Подробности обработки - в тексте.

с увеличением магнитного поля демонстрирует разнонаправленную тенденцию. В сплаве $\mathrm{Ni}_{48.8} \mathrm{Fe}_{51.2}$ размер зерна увеличивается с $31.5 \mu \mathrm{m}$ после предварительного отжига без поля до 32.2 и $49.4 \mu \mathrm{m}$ после предварительного отжига в поле 20 и $29 \mathrm{~T}$, а в сплаве $\mathrm{Ni}_{70} \mathrm{Co}_{30}$ - уменьшается с $78 \mu \mathrm{m}$ после отжига без поля до 70 и $49 \mu \mathrm{m}$ после отжига в поле 20 и 29 Т. Очевидно, это связано с торможением роста кубических зерен во втором сплаве и с увеличением скорости роста кубических зерен с направлением легкого намагничивания - в первом.

О протекании процессов возврата можно было непосредственно судить по сплаву $\mathrm{Ni}_{48.8} \mathrm{Fe}_{51.2}$, который отжигался в магнитном поле при температуре $500^{\circ} \mathrm{C}$, которая в обычных условиях без поля близка к температуре магнитного разупорядочения. Как уже отмечалось в работе [3] со ссылкой на работы [8,9], наличие магнитного момента дислокаций создает дополнительную энергию взаимодействия с внешним полем, препятствующую их движению, поэтому в сильных полях движение дислокаций затрудняется тем, что нужно прикладывать энергию для преодоления ориентирующего влияния поля. Этим в работе [10] объясняется эффект уменьшения максимального удлинения стали при растяжении в магнитном поле 5 Т. Кроме того, авторы монографии [11], а ранее авторы [12,13], указывают на наличие диффузионной магнитной аномалии, наблюдаемой в темпера- турной области перехода из парамагнитного состояния в ферромагнитное, которая заключается в том, что в ферромагнитных металлах с понижением температуры вблизи точки Кюри диффузионная подвижность уменьшается быстрее, чем это следует из уравнения Аррениуса, т.е. наблюдается аномальное уменьшение коэффициента диффузии. В настоящей работе отжиг без поля железоникелевого сплава происходил на границе ферромагнитного и парамагнитного состояний, когда магнитный порядок в существенной степени нарушен. Использование сильного магнитного поля 20 и 29 Т не дает разрушаться магнитному порядку, можно сказать, что отжиг происходит еще в ферромагнитном состоянии. Поэтому можно ожидать, что диффузионные процессы при магнитном отжиге протекают медленнее, чем при отжиге без поля, что, в свою очередь, задерживает процессы разупрочнения при возврате.

Другим явлением, происходящим при отжиге в магнитном поле, является ориентирующее влияние поля на формирование ячеек с направлением легкого намагничивания, совпадающем с направлением поля. В сплаве $\mathrm{Ni}_{48.8} \mathrm{Fe}_{51.2}$ при нагреве деформированного металла в поле энергетически выгоднее расти ячейкам с направлением легкого намагничивания $\langle 001\rangle$. При дальнейшей первичной рекристаллизации в обычных условиях это сказывается на формировании текстуры $\{100\}\langle 001\rangle$ в 
рекристаллизованных зернах, увеличивая ее остроту. В процессе отжига с медленным нагревом в магнитном поле сплава $\mathrm{Ni}_{70} \mathrm{Co}_{30}$ энергетически выгодно образовываться структурным элементам с направлением легкого намагничивания $\langle 111\rangle$. Однако вклад магнитной энергии слишком мал по сравнению с энергией, запасенной при холодной деформации и энергией границ зерен, поэтому приложение магнитного поля в этом сплаве не может предотвратить образование кубической текстуры, однако существенно снижает остроту кубической ориентировки (см. таблицу). Об ориентирующем влиянии поля на создание областей с направлением легкого намагничивания $\langle 111\rangle$ можно судить по слабому увеличению объемной доли компоненты текстуры деформации $\{112\}\langle 111\rangle$, остающейся в текстуре первичной рекристаллизации после магнитных отжигов (см. таблицу).

\section{Заключение}

Установлено, что приложение сильного постоянного магнитного поля при отжиге замедляет процессы возврата. Это объясняется замедлением процессов диффузии под действием внешнего магнитного поля, а также затруднением движения дислокаций из-за воздействия внешнего поля на их магнитные моменты.

Энергия магнитной анизотропии вносит вклад в формирование кристаллографической текстуры после отжига в магнитном поле. В сплаве с направлением легкого намагничивания $\langle 001\rangle$ отжиг в магнитном поле увеличивает остроту кубической текстуры и повышает средний размер зерна. В сплаве с направлением легкого намагничивания 〈111〉 после отжига в поле острота кубической текстуры падает, а средний размер зерна уменьшается.

Эксперименты по определению ориентации зерен на поверхности текстурованных лент методом EBSD проведены в отделе электронной микроскопии, съемка дилатометрических кривых - в отделе магнитных измерений ЦКП Испытательный центр нанотехнологий и перспективных материалов Института физики металлов УрО РАН.

Работа выполнена в рамках государственного задания ФАНО России (тема „Магнит“, № 01201463328). Авторы выражают благодарность за поддержку организации LNCMI-CNRS, члену Европейской лаборатории магнитных полей (EMFL).

\section{Список литературы}

[1] Rivoirard S. // JOM. 2013. Vol. 65. P. 901-909.

[2] Zhang Y., Esling C., Zhao X., Zuo L. // Mater. Sci. Forum. 2010. Vol. 638-642. P. 202-207.

[3] Gervasyeva I.V., Beaugnon E., Milyutin V.A., Volkova E.G., Rodionov D.P., Khlebnikova Yu.V., Shishkin D.A. // Phisica B. 2015. Vol. 468-469. P. 66-71.
[4] Тикадзуми C. Физика ферромагнетизма. Магнитные характеристики и практические применения. М.: Мир, 1987. C. 51.

[5] Ray R.K. // Acta Met. Mater. 1995. Vol. 43. N 10. P. 3861-3872.

[6] Гервасьева И.В., Соколов Б.К., Родионов Д.П., Хлебникова Ю.В., Подкин Я.В. // ФММ. 2003. Т. 96. № 2. С. 95-101.

[7] Гервасьева И.В., Милютин В.А., Бинон Э., Хлебникова Ю.В., Родионов Д.П. // ФММ. 2016. Т. 117. № 5. C. $513-518$.

[8] Vicena F. // Czech. J. Phys. 1955. Vol. 5. N 4. P. 480-501.

[9] Seeger A., Kronmuller H., Rieger H., Traubler R. // J. Appl. Phys. 1964. Vol. 35. P. 740-748.

[10] Ефимова Т.В., Полотнюк В.В. // Укр. физ. журн. 1981. T. 26. № 7. C. $1149-1153$.

[11] Мазанко В.Ф., Покоев А.В., Миронов В.М. и др. Диффузионные процессы в металлах под действием магнитных полей и импульсных деформаций. Т. 1. М.: Машиностроение-1; Самара: Самарский университет, 2006. $346 \mathrm{c}$.

[12] Kucera J., Kozak L., Mehrer H. // Phys. Stat. Sol. A. 1984. Vol. 81. P. 497-505.

[13] Salje G., Feller-Kniepmeier M. // J. Appl. Phys. 1977. Vol. 48. N 5. P. $1833-1839$. 